\title{
OSTEOMA OSTEOIDE: RESECCION PERCUTANEA GUIADA POR TOMOGRAFIA COMPUTADA
}

Drs. Enrique Bosch $\mathbf{O}^{(1)}$, Roberto Raimann $B^{(2)}$, Patricio Vargas $H^{(1)}$, Pablo Soffia $\boldsymbol{S}^{(1)}$, Gonzalo Delgado $\boldsymbol{P}^{(1)}$, Julia Alegría $B^{(1)}$, Virginia Martínez $C^{(3)}$.

1. Servicio de Tomografía Computada y Resonancia Magnética, Departamento de Imágenes, Clínica Alemana de Santiago.

2. Departamento de Urgencia Escolar. Clínica Alemana de Santiago.

3. Instituto de Anatomía Patológica, Clínica Santa María.

\begin{abstract}
Percutaneous resection of osteoid osteomas is a technique of interventional radiology that is becoming more commonly used. We reported our experience with this technique in 9 patients to evaluate the medium-term outcome of this technique of percutaneous resection.
\end{abstract}

Key words: CT, Osteoid osteoma, Resection.

Resumen: La resección percutánea del osteoma osteoide es una técnica de radiología intervencional que ha empezado a ser utilizada en forma más frecuente. Reportamos nuestra experiencia en 9 casos evaluando los resultados obtenidos.

Palabras claves: CT, Osteoma osteoide, Resección.

\section{Introducción}

El osteoma osteoide es un tumor óseo benigno de adultos jóvenes, que se ubica preferentemente en la cortical de los huesos largos de las extremidades inferiores. No tiene potencial de crecimiento y su tamaño rara vez supera $1,5 \mathrm{~cm}$, pese a que la esclerosis que lo rodea le da un aspecto mayor. Son relativamente comunes, constituyendo alrededor del $10 \%$ de los tumores óseos ${ }^{(1)}$. Su manifestación clínica típica es el dolor nocturno, que responde con ácido acetilsalicílico. La radiografía simple, el cintigrama óseo y la tomografía computada (TC), generalmente son suficientes para establecer el diagnóstico.

El tratamiento tradicional consiste en la resección abierta, en bloque, cuyas mayores dificultades son la localización del nido y la desproporción del abordaje quirúrgico respecto al tamaño de la lesión. Recientemente se han propuesto alternativas percutáneas, como la resección guiada por TC, descrita por Doyle y King ${ }^{(2)}$, Voto et al. ${ }^{(3)}$, y

Bosch E, y cols. Osteoma osteoide: Resección percutánea guiada por tomografía computada. Rev Chil Radiol 2005; 11: $45-50$.

Correspondencia: Dr. Enrique Bosch 0.

E-mail: ebosch@alemana.cl
Kohler et al.(4), la termocoagulación con radiofrecuencia ${ }^{(5)}$ y la coagulación con láser ${ }^{(6)}$.

La resección percutánea guiada por TC es una técnica de radiología intervencional, que se utiliza cada vez con mayor frecuencia ${ }^{(7)}$. Publicamos nuestra experiencia en pacientes tratados con esta técnica.

\section{Materiales y método}

Población. Entre agosto del 2001 y noviembre del 2004 fueron resecadas por vía percutánea nueve lesiones radiológicamente diagnosticadas como osteomas osteoides en 9 pacientes. El diagnóstico se estableció por la clínica y hallazgos radiológicos. Nuestra población fue de siete hombres y dos mujeres, con un promedio de edad de 15 años y con un rango de 9 a 20 años. Todas las lesiones eran corticales y en extremidad inferior. Se ubicaron cinco en fémur, dos en tibia, una en astrágalo y una en calcáneo. De los pacientes tratados, uno en tibia y otro en fémur, ya habían sido sometidos a tratamiento con cirugía abierta, la que no había conseguido la extracción del nido.

Técnica de resección. El tratamiento se planteó al paciente posterior a la discusión con el traumatólogo tratante. Se obtuvo consentimiento informado y pruebas de coagulación. El procedimiento se efectuó en la sala de TC, en condiciones estériles, con el paciente en ayunas y, en todos los casos, bajo anestesia general, lo cual permitió una inmovilidad completa. Se usó profilaxis con cefazolina 1 hora antes y 12 horas posterior al procedimiento.

Para la resección percutánea, en siete pacientes se empleó instrumental coaxial, con extremos dentados (Figuras 1 y 2), cuyos diámetros varían entre $3 \mathrm{~mm}$ y $1 \mathrm{~cm}$. La lesión se localizó con una marca en la piel. Utilizando cortes finos de TC de 2-3 $\mathrm{mm}$ se planificó la aproximación, intentando demostrar el trayecto más corto y seguro, libre de estructuras neurovasculares. Posteriormente se preparó un campo quirúrgico y se infiltró el periostio con anestésico local, usualmente 4-5 cc de lidocaína diluida. Se efectuó una pequeña incisión de $1 \mathrm{~cm}$ con bisturí y con un estilete fino, se puncionaron las 


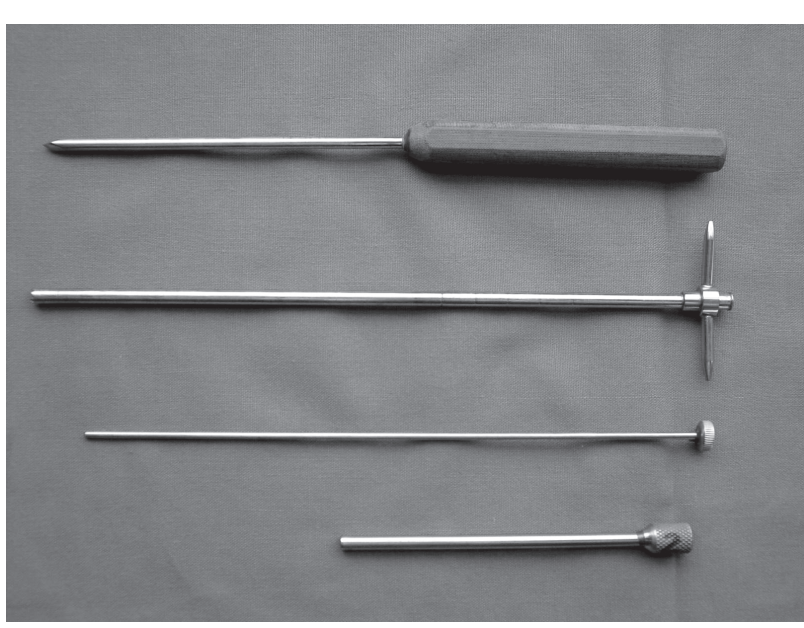

Figura 1. Sistema de agujas canuladas, de biopsia ósea, para uso intraoperatorio.
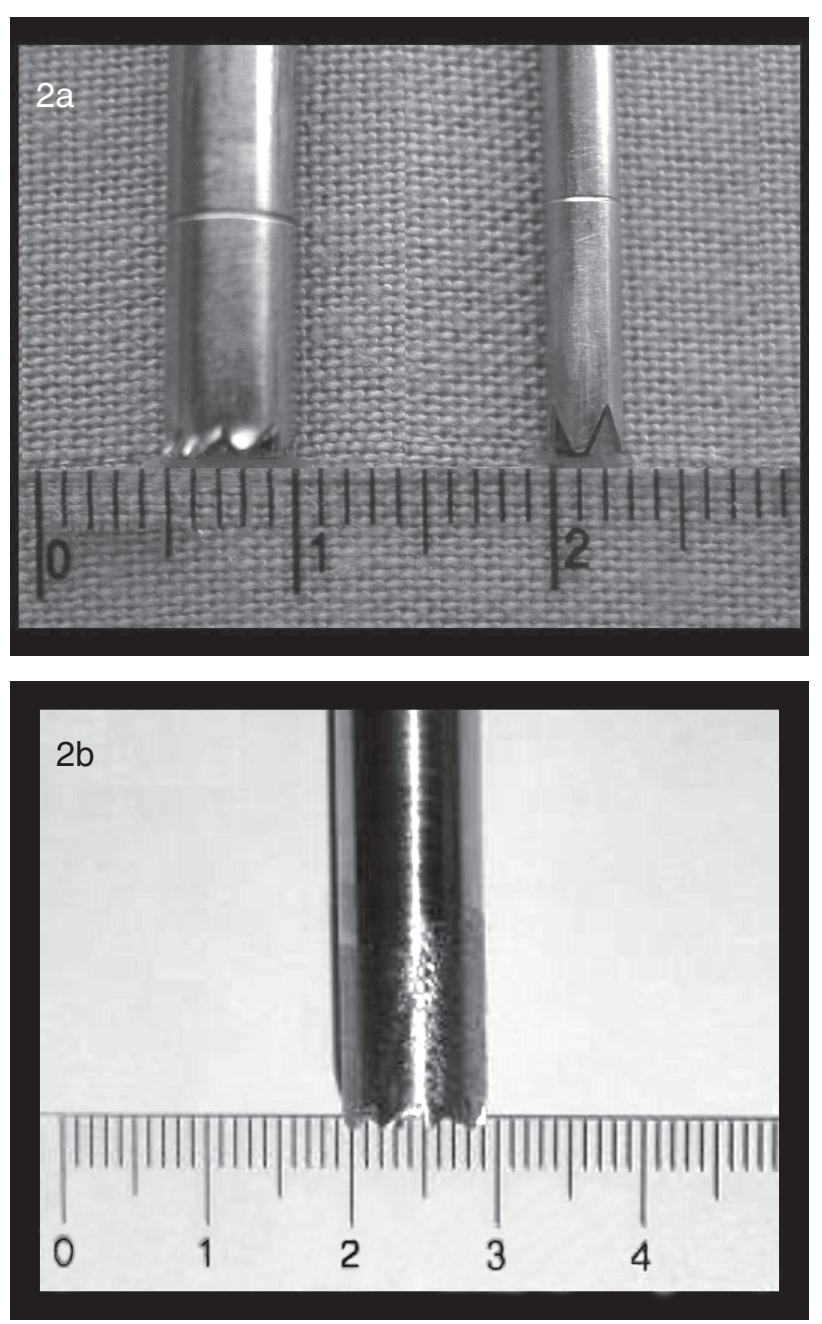

Figuras 2 a $\boldsymbol{y}$ b. Sistema de agujas canuladas, con su extremo dentado.

partes blandas y la cortical, intentando establecer un trayecto directo hasta el nido de la lesión. A través de él se introdujeron cánulas de tamaño creciente, con movimientos de rotación sobre su eje mayor, lo que permitió avanzar el extremo dentado. En los dos últimos pacientes se utilizaron brocas coaxiales conectadas a un sistema motorizado (Figura 3), lo que facilita el acceso a la lesión, pero que, sin embargo, produce una mayor fragmentación del material.

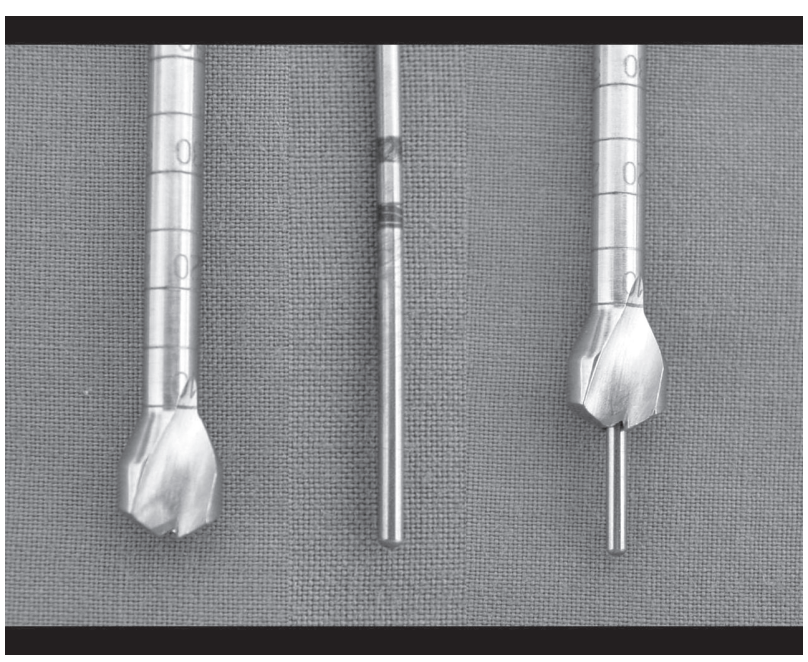

Figura 3. Instrumental coaxial motorizado.

Debido a que hay que atravesar hueso cortical engrosado de gran resistencia, es necesario apoyarse con pequeños golpes de martillo. Al retirar las cánulas se obtiene material óseo, en el cual a veces es posible reconocer fragmentos del nido. Este material se envió a estudio histopatológico. Finalmente se confirmó la extracción completa del nido tumoral, con cortes de TC de 2-3 mm (Figuras 4 y 5$)$.

En un paciente se agregó a la resección un tratamiento con radiofrecuencia, la que se efectuó con una aguja electrodo, con un extremo expuesto de $5 \mathrm{~mm}$, que se mantuvo 5 minutos a $90^{\circ} \mathrm{C}$ (Figura $6)$. En todos, la resección del nido se consideró completa (Figura 7).

El tiempo promedio del procedimiento, desde el inicio de la anestesia, fue de $1,30 \mathrm{hr}$, variando entre 45 minutos y 2 horas.

Seguimiento. El seguimiento de estos pacientes varió entre 6 y 44 meses, con un promedio de 28 meses. Para cada paciente se recolectó información retrospectiva y prospectiva, incluyendo el resultado histológico, la evolución clínica inmediata y alejada, y eventuales complicaciones. La mejoría se estableció por la rápida y definitiva desaparición del dolor y en algunos casos por el seguimiento con radiografías o TC. En ningún paciente se repitió el procedimiento.

Antecedentes clínicos: Los datos clínicos de todos los pacientes se presentan en la tabla I. Se confirma que el osteoma osteoide es más frecuente en la segunda década de la vida, su presentación es bastante clásica, con dolor preferentemente nocturno en todos los pacientes, y alivio con ácido 
acetilsalicílico en 5 pacientes. El intervalo entre los síntomas y el diagnóstico fue en promedio 9,8 meses con un rango entre 2 meses y 2 años.

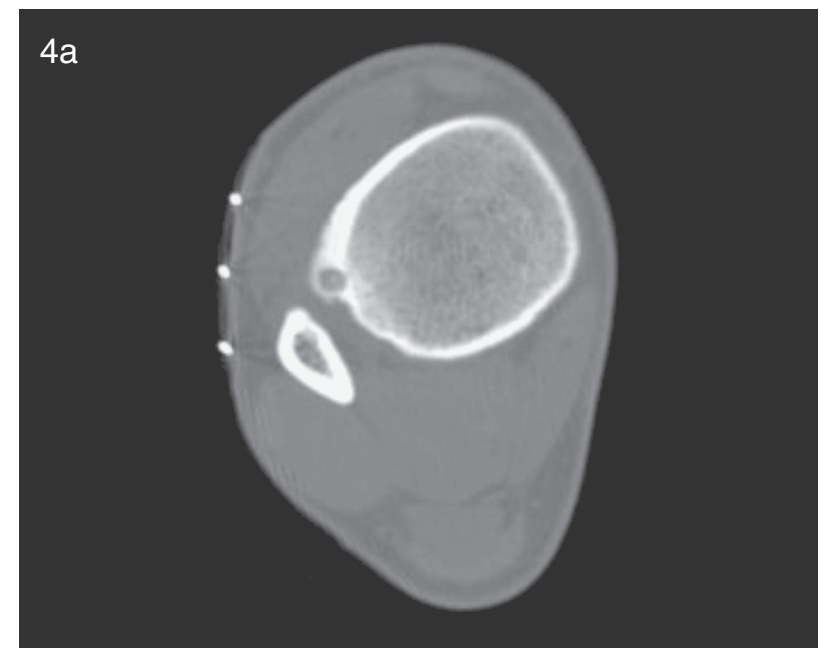

Figura 4a. Osteoma osteoide de tibia derecha. a) Marca cutánea e identificación del nido.

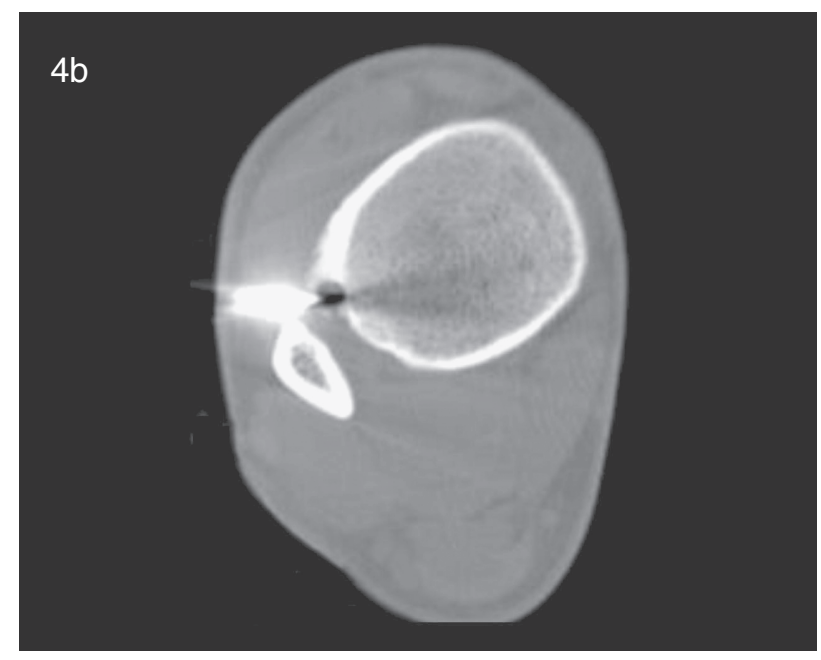

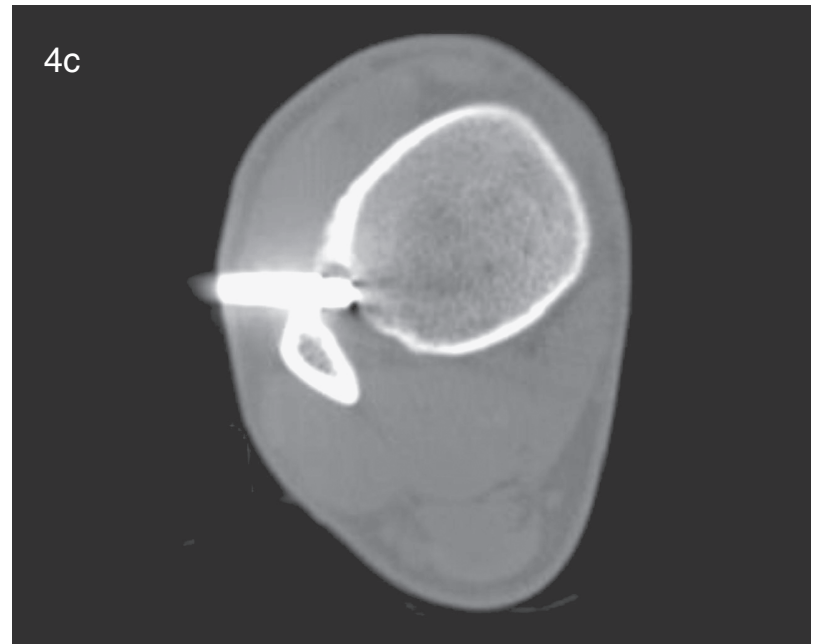

Figura 4c. Osteoma osteoide de tibia derecha. c) Sistema coaxial resecando la lesión.

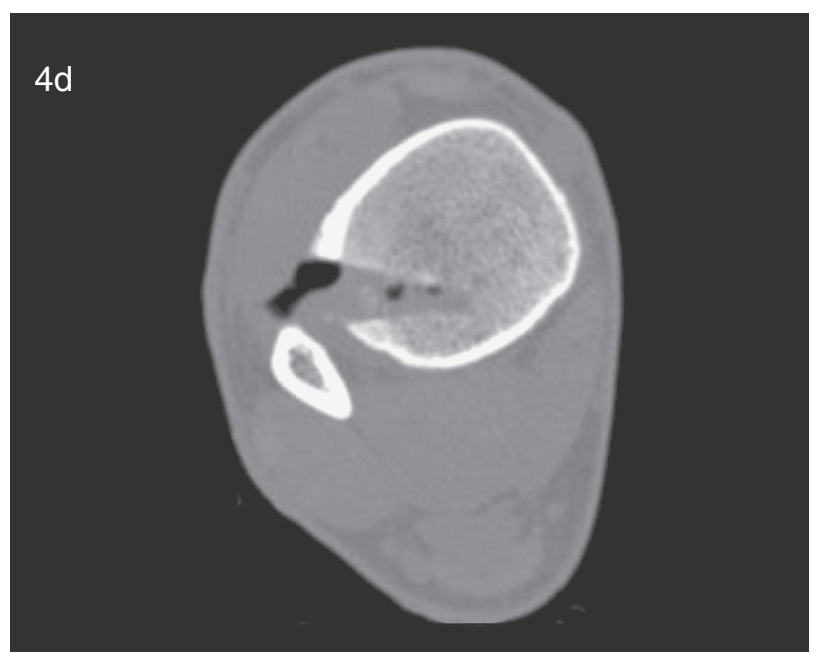

Figura 4d. Osteoma osteoide de tibia derecha. d) Se comprueba la resección completa.

Figura 4b. Osteoma osteoide de tibia derecha. b) Trayecto inicial con estilete.

Tabla I. Antecedentes clínicos pre y post procedimiento.

\section{Paciente Localización Histología Dolor nocturno Evol.Clínica \\ № Edad Sexo}

\begin{tabular}{|rrrllll|}
1 & 10 & $\mathrm{~F}$ & Fémur izq. proximal & Nido $(-)$ & sí & Buena \\
2 & 9 & M & Fémur izq. proximal & Nido (+) & sí & Buena \\
3 & 16 & M & Calcáneo der. & Nido (+) & sí & Buena \\
4 & 16 & M & Astrágalo izq. & Nido (+) & sí & Buena \\
5 & 20 & M & Tibia der. distal & Nido (+) & sí & Buena \\
6 & 14 & F & Fémur izq. proximal & Nido (+) & sí & Buena \\
7 & 16 & M & Fémur der. distal & Nido (-) & sí & Buena \\
8 & 10 & M & Tibia der. 1/3 medio & Nido (+) & sí & Buena \\
9 & 16 & M & Fémur der. distal & Nido (-) & sí & Buena \\
\hline
\end{tabular}




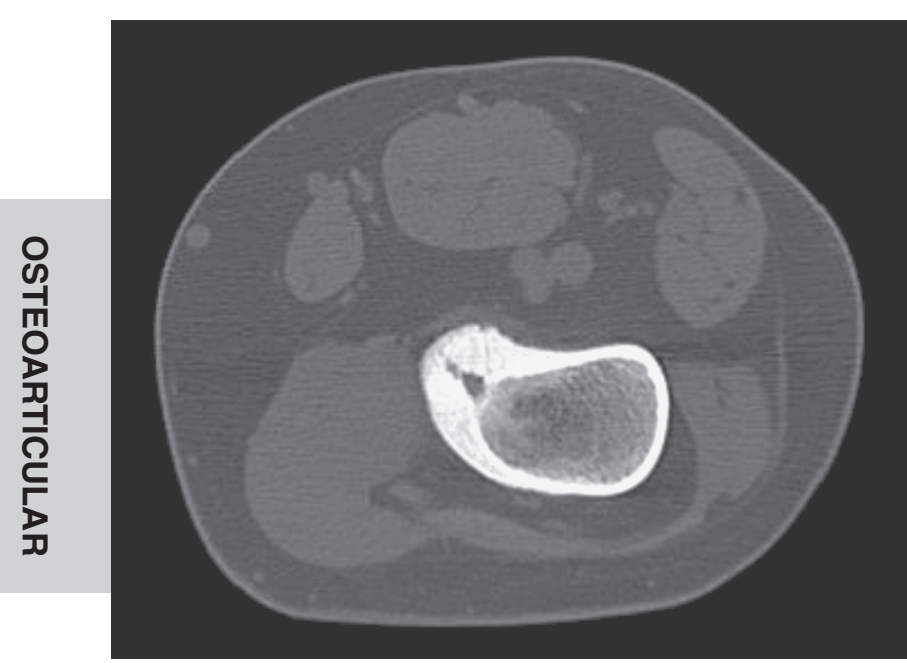

Figura 5a. Osteoma osteoide de la cortical posterior distal del fémur derecho, de difícil acceso. a) Identificación del nido.

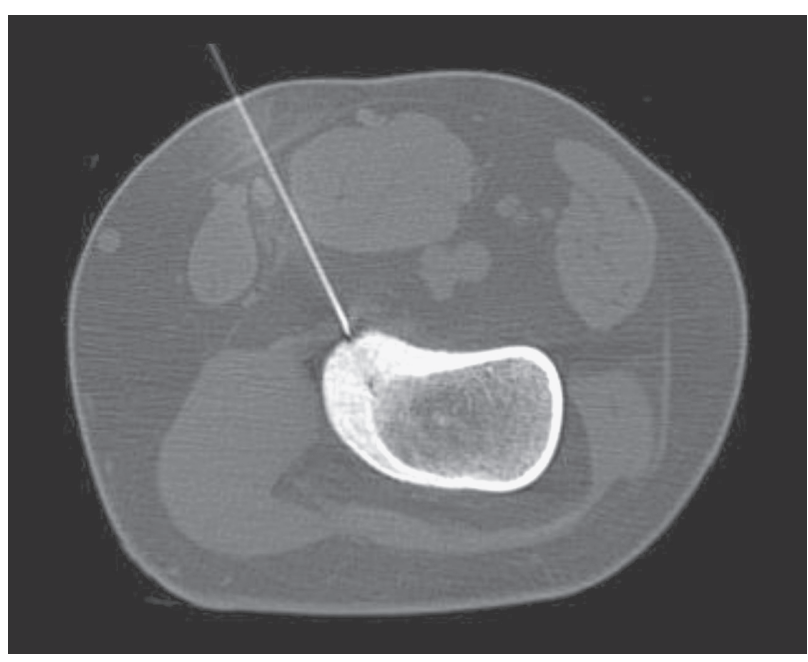

Figura 5b. Osteoma osteoide de la cortical posterior distal del fémur derecho, de difícil acceso. b) Acceso por vía posterior.

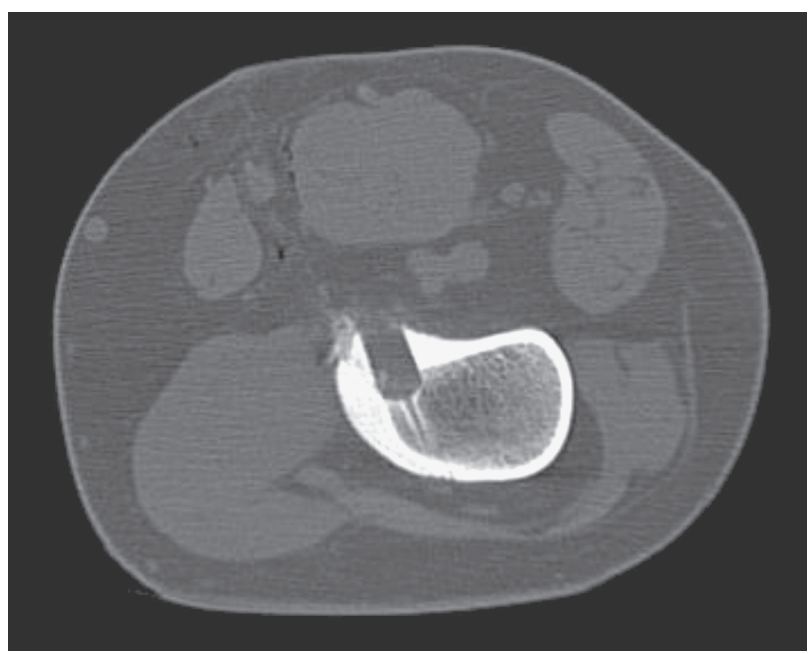

Figura 5c. Osteoma osteoide, de la cortical posterior distal del fémur derecho, de difícil acceso. c) Se comprueba resección completa del nido.

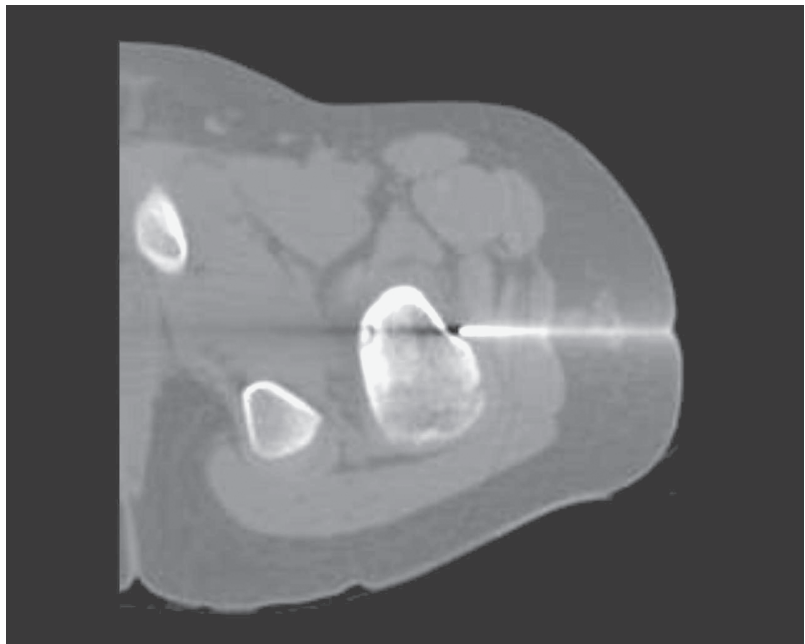

Figura 6a. a) Osteoma osteoide fémur izquierdo.

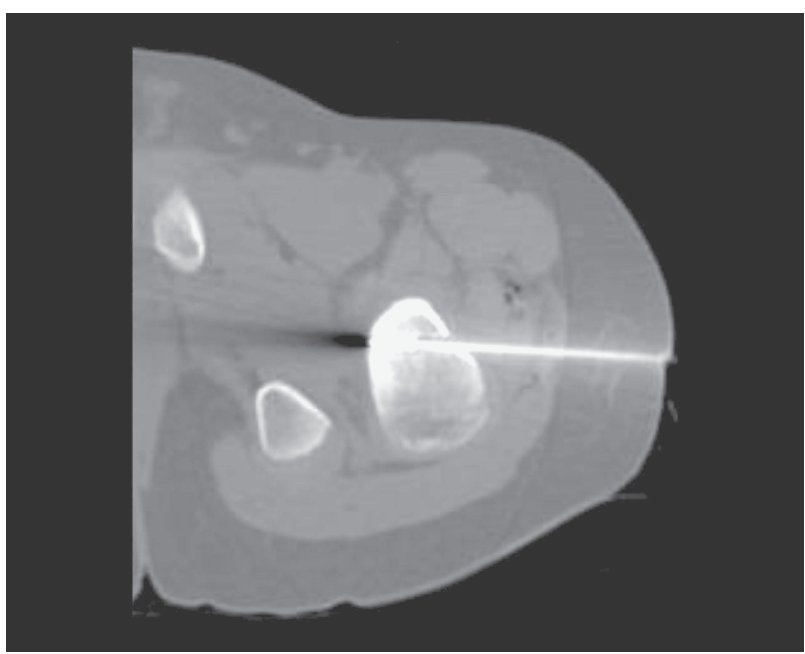

Figura 6 b. b) Tratamiento con radiofrecuencia posterior a la extracción percutánea.

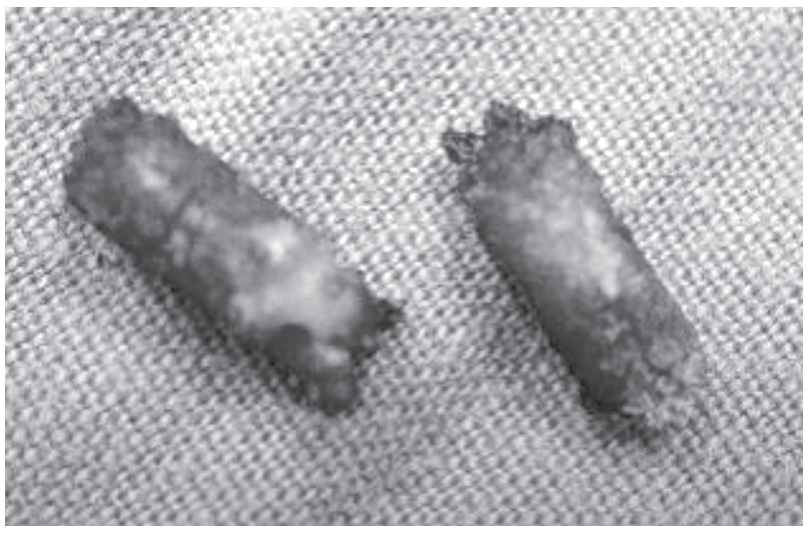

Figura 7. Muestras del tejido en el cual es posible reconocer fragmentos del nido. 


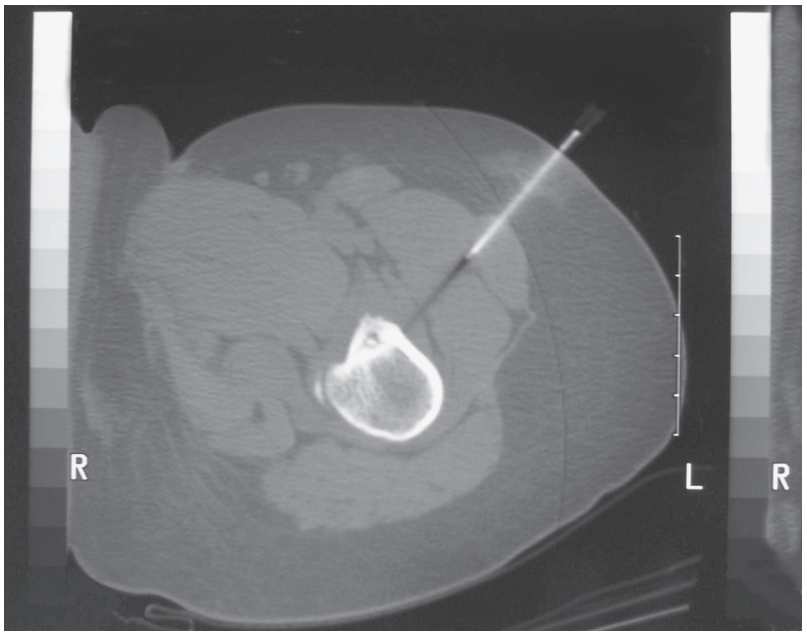

Figura 8a. Osteoma osteoide de la cortical anterior del fémur derecho proximal. a) Identificación del nido.

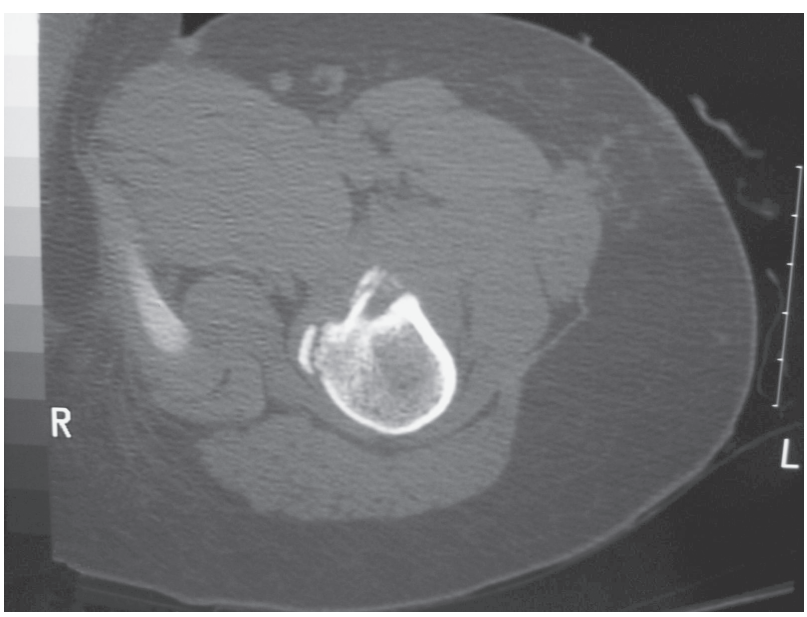

Figura 8b. Osteoma osteoide de la cortical anterior del fémur derecho proximal. b) Cortes post-procedimiento con imagen que sugiere persistencia parcial del nido.

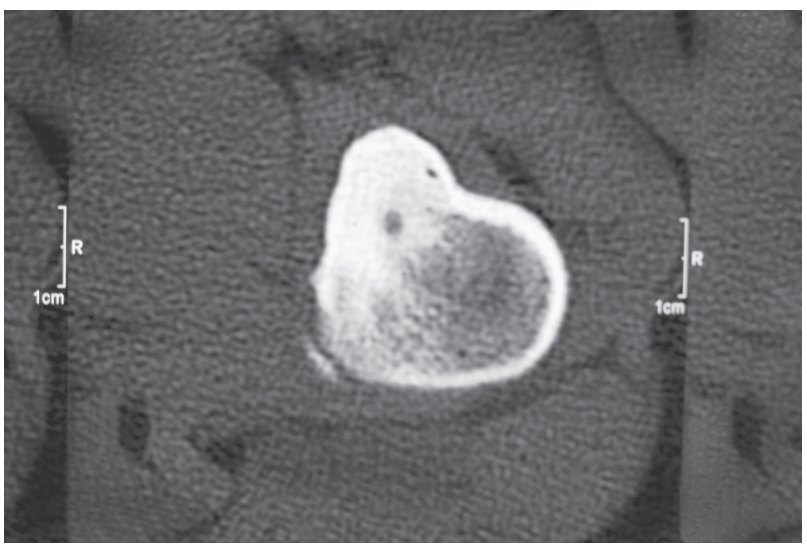

Figura 8c. Osteoma osteoide de la cortical anterior del fémur derecho proximal. c) Control al año, con extensa esclerosis y pequeña área radiolúcida central.

Histología: La presencia del nido o fragmentos del mismo en el estudio histológico confirmó el diagnóstico de osteoma osteoide en seis casos. En tres casos no se identificó el nido, sin embargo en dos de ellos el material estudiado sugirió el diagnóstico y en el otro la biopsia concluyó sólo la presencia de tejido óseo fragmentado, sin evidencias de malignidad. En ningún caso el patólogo planteó diagnósticos alternativos.

Evolución Clínica: El dolor desapareció rápidamente en todos los pacientes. El primero de los pacientes tratados presentó alivio inmediato de sus molestias. Sin embargo, consultó al año con dolor leve, y una nueva TC demostró un área de esclerosis con un centro radiolúcido en la zona de punción (Figura 8). Las molestias se aliviaron rápidamente en forma espontánea. En nuestro análisis retrospectivo, revisando las imágenes, pensamos que probablemente el nido se resecó parcialmente. Los ocho pacientes restantes han permanecido libres de molestias en el seguimiento.

El tiempo de hospitalización de todos los pacientes fue de $24 \mathrm{hr}$. Se les permitió retomar sus actividades en forma inmediata, con carga de las extremidades. Sólo se les restringió la actividad deportiva durante 3 meses.

Complicaciones: No observamos complicaciones mayores. En un caso se constató granulación de la pequeña incisión quirúrgica, debido a un retiro precoz de los puntos.

Resultados del tratamiento: La resección percutánea guiada bajo TC es efectiva. La mejoría clínica fue de un $100 \%$ de los pacientes.

\section{Discusión}

El osteoma osteoide es un tumor benigno de adultos jóvenes, que se ubica en los huesos largos a nivel de las metafisis, preferentemente en las extremidades inferiores. La manifestación clínica típica es el dolor nocturno, que responde al uso de ácido acetilsalicílico. La radiografía simple y la TC generalmente son suficientes para establecer el diagnóstico. La TC también da información sobre la localización precisa de la lesión y el tamaño del nido. Estos parámetros orientan sobre la estrategia terapéutica: resección quirúrgica abierta o bien resección percutánea guiada bajo TC.

Se ha descrito que el osteoma osteoide puede involucionar con los años; sin embargo, la resección a menudo es necesaria para aliviar el dolor y obtener la confirmación histológica.

La resección quirúrgica abierta en bloque ha sido el tratamiento habitual, para extraer en forma completa el nido y obtener la remisión de los síntomas. Esta opción de tratamiento tiene la desventaja de utilizar un abordaje que no guarda relación con el tamaño de la lesión, especialmente en zonas de difícil acceso, como la región acetabular, pudiendo requerir osteosíntesis e injertos óseos, además de la dificultad que encuentra el traumatólogo para ubicar con exactitud la lesión. Se ha 
utilizado el cintigrama óseo intraoperatorio para localizar el nido y monitorizar su resección ${ }^{(8)}$. También se pueden obtener radiografías del trozo resecado, con el objeto de identificar el nido en la pieza quirúrgica. En nuestra serie, dos pacientes habían sido sometidos a cirugía abierta, sin éxito.

La dificultad en encontrar el nido y el deseo de limitar el tamaño de la resección ósea ha favorecido el desarrollo de la resección percutánea bajo TC, así como otras técnicas percutáneas alternativas.

Es posible realizar la resección percutánea cuando la extracción del osteoma osteoide no implica riesgos, pues se encuentra alejado de estructuras vasculares y nerviosas, no hay infección en las partes blandas, o no están en huesos muy pequeños, como por ejemplo los huesos del carpo.

Los resultados de esta serie confirman la eficacia de esta técnica mínimamente invasiva, que permite casi siempre obtener la resección completa de la lesión, con confirmación histológica, hospitalización de sólo 24 horas y un rápido reintegro a las actividades cotidianas.

\section{Conclusión}

Por las razones anteriormente expuestas consideramos la técnica percutánea bajo TC como el tratamiento de elección cuando es técnicamente posible.

\section{Bibliografía}

1. Greenspan A. Benign bone-forming lesions: osteoma, osteoide osteoma, and osteoblastoma. Skeletal Radiol 1993; 22:485-500.

2. Doyle T, King K, Percutaneous removal of osteoide osteomas using CT control. Clin Radio 1989; 40:514 -517.

3. Voto SJ, Cook AJ, Weiner DS, Ewing JW, Arrington LE. Treatment of osteoide osteoma by computed tomography guided excision in the pediatric patient. J Pediatri Orthop 1990; 10:510-513.

4. Kohler R, Mazoyer JF, Besse JL, Bascoulergue Y. Tratment of osteoide osteoma with percutaneous resection under computerized tomography control: apropos of 5 cases. Rev Chir Orthop Réparatrice Appar Mot; 76:284-287 (French).

5. Rosenthal DI, Hornicek FJ, Wolfe MW, Jennings LC, Gebhardt MC, Mankin HJ Percutaneous radiofrequency coagulation of osteoid osteoma compared with operative treatment. J Bone Joint Surg Am 1998; 80:815-821.

6. Gangi A, Dietemann JL, Gasser B, et al. Interventional radiology with laser in bone and joint. Radiol Clin North Am 1998; 36:547-557.

7. Sans N, Galy-Fourcade D, Assoun J, et al. Osteoid Osteoma: CT-guided percutaneous resection and follow-up in 38 patients. Radiology 1999; 212:687-692.

8. O'Brien TM, Murray TE, Malone LA, et al. Osteoid osteoma escisión with scintimetric guidance. Radiology 1984; 153: 543-544. 